\title{
Causative factors of liver fibrosis in HIV- infected patients. A single center study
}

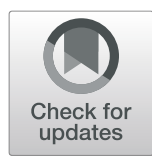

Theodoros Androutsakos ${ }^{1 *}$, Maria Schina ${ }^{2}$, Abraham Pouliakis ${ }^{3}$, Athanasios Kontos ${ }^{4}$, Nikolaos Sipsas ${ }^{4,5}$ and

Gregorios Hatzis ${ }^{6}$

\begin{abstract}
Background: Liver disease is a leading cause of morbidity and mortality among Human Immunodeficiency virus (HIV) infected patients; however no consensus exists on HIV-related risk factors for it. The aim of this study was to identify risk factors for liver fibrosis/cirrhosis in a cohort of Greek HIV-infected patients.

Methods: Patients attending the HIV outpatient clinic of Pathophysiology Department at «Laiko» General Hospital in Athens, Greece, between December 2014 and December 2017 were eligible for inclusion. Inclusion criteria were confirmed HIV infection and age $>18$ years. Exclusion criteria were Body-Mass index (BMI) $>40$, liver metastases of malignant diseases and concurrent or previous chemotherapy.

Liver stiffness (LS) was measured using Vibration Controlled Transient Elastography (TE) and laboratory tests were acquired in all patients. Patients were classified in 2 groups: those with mild or no fibrosis (equivalent to Metavir score F0-F2) and those with significant fibrosis (equivalent to Metavir score F3-F4).
\end{abstract}

Results: A total of 187 consecutive patients were included in this study. Median TE value was 5.1 kilopascals (KPa) (range 2.8-26.3), with 92.5\% (173/187) of the patients having no/mild fibrosis and 7.4\% (14/187) significant fibrosis. On multivariate logistic regression analysis older patient's age, abnormal serum aspartate aminotransferase (AST) value, Hepatitis $\mathrm{C}$ virus (HCV) infection, alcohol abuse, CD4/CD8 ratio and an increased number of liver related events (LREs) were significantly correlated with liver fibrosis/cirrhosis.

Conclusions: In our cohort of HIV-infected individuals HCV/HIV co-infection, older age, alcohol abuse and CD4/CD8 ratio seem to correlate with fibrogenesis in the liver.

Keywords: HIV infection, Liver fibrosis, CD4/CD8 ratio, HCV/HIV coinfection, Liver stiffness, Transient Elastography

\section{Background}

Human immunodeficiency virus (HIV) infection constitutes a major global public health issue, with 37 million people worldwide, 34 of them being adults, being infected from HIV [1]. After the initiation of antiretroviral treatment (ART) back in 1996, the leading causes of morbidity and mortality among people living with HIV in industrialized countries has shifted from opportunistic

\footnotetext{
*Correspondence: T_Androutsakos@yahoo.gr

${ }^{1}$ Department of Pathophysiology, Medical School, National and Kapodistrian University of Athens, Mikras Asias 75, 11527 Athens, Greece

Full list of author information is available at the end of the article
}

infections and AIDS-related neoplasms to non-AIDS defining events, especially cardiovascular and liver diseases [2-5]. In particular, liver-related deaths in HIV infected patients occur 10 times more often in comparison with the general population [6], ranging from 7 to $14 \%$ in different studies $[7,8]$.

Liver conditions complicating HIV infection have also changed during the years. Starting from the early AIDSperiod, when the major problem was hepatitis $B$ with or without hepatitis D infection, moving to the 2000s with the rise of hepatitis $\mathrm{C}$ virus (HCV) infection and nowadays with the alcoholic and non-alcoholic fatty liver

(c) The Author(s). 2020 Open Access This article is licensed under a Creative Commons Attribution 4.0 International License, which permits use, sharing, adaptation, distribution and reproduction in any medium or format, as long as you give appropriate credit to the original author(s) and the source, provide a link to the Creative Commons licence, and indicate if changes were made. The images or other third party material in this article are included in the article's Creative Commons licence, unless indicated otherwise in a credit line to the material. If material is not included in the article's Creative Commons licence and your intended use is not permitted by statutory regulation or exceeds the permitted use, you will need to obtain permission directly from the copyright holder. To view a copy of this licence, visit http://creativecommons.org/licenses/by/4.0/ The Creative Commons Public Domain Dedication waiver (http://creativecommons.org/publicdomain/zero/1.0/) applies to the data made available in this article, unless otherwise stated in a credit line to the data. 
disease, liver involvement has been a major issue in the history of HIV infection [9].

Liver biopsy (LB) remains the gold-standard for diagnosis and staging of liver fibrosis, but its application in everyday clinical practice has many limitations (need for an experienced personnel, high cost, sampling errors, intraobserver variability) and complications (bleeding, pain and rarely death) [10-13]. However, in the last decade, advances in the field of medical technology and imaging allow clinicians to estimate liver status with no invasive procedures. Among them transient elastography (TE) seems to provide the most reliable results with high creditability, being superior to serum biomarkers which sometimes underestimate the magnitude of liver disease [14-18].

Although liver fibrosis is not an uncommon finding in HIV infected patients, there is no agreement over the HIV-related causative risk factors [19-24]. The aim of this study was to identify the main risk factors for liver fibrosis/cirrhosis in a cohort of Greek HIV-infected patients.

\section{Methods}

All consecutive patients attending the HIV outpatient clinic of the Pathophysiology department at «Laiko» General Hospital in Athens, Greece, between December 2014 and December 2017 were eligible for inclusion in this study. Inclusion criteria were confirmed HIV infection and age $>18$ years. Exclusion criteria were Body Mass Index $(\mathrm{BMI})>40$, malignant disease with metastases in the liver and concurrent or previous chemotherapy. The protocol of the study was reviewed and approved by «Laiko» General Hospital's ethical committee, informed consent was obtained from each patient included in the study and the study protocol conforms to the ethical guidelines of the Declaration of Helsinki (Edinburgh, 2000).

Liver stiffness (LS) measurement and laboratory workup (including serum transaminases, cholesterol, highdensity lipoproteins (HDL), low-density lipoproteins (LDL), albumin, blood sugar and thyroid stimulating hormone (TSH) serum levels) as well as HIV-infection surrogate markers (CD4 count, CD4/CD8 ratio and HIV viral load) were performed in all patients that met the inclusion criteria. Medical history, including quantity of daily, as well as weekly, alcohol intake, was obtained by interviewing patients and/or through their medical charts. Liver fibrosis was assessed by Vibration Controlled Transient Elastography (TE) using FibroScan (EchoSens, Paris, France) performed at the time of blood collection for laboratory work-up. All TE were performed by the same experienced operator and all blood samples were analyzed in the same laboratory. HIV infection staging has been performed according to Centers for Disease Control and Prevention (CDC) classification system [25]. Duration of HIV infection was defined based on the first positive test for HIV infection by western blotting, while duration of ART regimens was assessed according to patients' drug prescriptions. A patient was characterized as diabetic if he was on antidiabetic treatment or if his/her blood sugar level during testing was $>126 \mathrm{mg} / \mathrm{dl}$ or $>200 \mathrm{mg} / \mathrm{dl}$ for fasting or non-fasting patient respectively and hyperlipidemic if he was on hypolipidemic treatment or if his/her fasting cholesterol levels was $>200 \mathrm{mg} / \mathrm{dl}$ and/or LDL was > $130 \mathrm{mg} / \mathrm{dl}$ in double check at least 3 months apart [26, 27]. As liver related event (LRE) was defined every event associated with the liver like transaminasemia, acute viral hepatitis, portal vein thrombosis and drug-induced liver injury, with transaminasemia being defined as the existence of serum transaminases levels $>3 \mathrm{x}$ upper limit of normal (ULN), according to reference laboratory values, and hyperbilirubinemia as total serum bilirubin levels $>2 \times$ ULN. As drug induced liver injury was defined every event of transaminasemia or cholestasis attributed to a certain drug taken by the patient and requiring this drug's discontinuation. As acute viral hepatitis was regarded any event of transaminasemia attributed to a specific virus (t.ex. Epstein-Barr virus (EBV), Hepatitis A virus (HAV), Herpes simplex virus (HSV), Varicella zoster virus (VZV)). As other liver related events were regarded complications affecting the liver but not already mentioned, like acquired immune deficiency syndrome (AIDS) cholangiopathy, liver cancer, autoimmune diseases of the liver or Budd-Chiari syndrome. As alcohol abuse was defined drinking 8 or more drinks per week for women and 15 or more drinks per week for men or binge drinking (defined as 4 drinks for women and 5 drinks for men-in about 2 h) on 5 or more days in 1 month, according to National Institute on Alcohol and Alcoholism guidelines [28].

Patients were considered to have no/mild liver fibrosis (equivalent to Metavir score F0-F2) with LS values $<8.1$ Kilopascals $(\mathrm{KPa})$ if they were co-infected with $\mathrm{HBV},<$ 9.4 $\mathrm{KPa}$ if they were co-infected with $\mathrm{HCV}$ or had alcoholic steatosis and with $<8.4 \mathrm{KPa}$ for patients not included in the above groups. Patients allocated in the 'significant fibrosis' group (equivalent to Metavir score F3-F4) were those with LS values higher than the abovementioned ones [14-19, 22].

Demographic, clinical and laboratory characteristics stratified by the severity of liver fibrosis were compared. A correlation analysis estimated possible impacts on liver fibrosis determined by TE. For parameters expressed in numeric form, the Kruskal-Wallis test was applied in order to identify differences between patients in the no/mild and in the significant fibrosis group. To estimate the effect in univariate analysis it was estimated 
the odds ratio (OR) for the categorical parameters and the epsilon-squared $\left(\varepsilon^{2}\right)$ for the parameters that were measurable in numeric form [29], both with the 95\% confidence interval (CI). Note that the effect characterization $\varepsilon^{2}$ according to its value is: $0-0.002$ : minor effect, 0.002-0.04: small effect, 0.04-0.10: intermediate effect and 0.10-0.20: significant effect.

Categorical variables were compared using the Chisquared test. Multivariate analyses were performed by multiple logistic regression models using backwards elimination; the $p$ value to remove a variable from the model was set to be higher than 0.05 and the statistical significance $p$ values were set to be $<0.05$. In addition, only first order interactions between parameters were allowed. SAS 9.4 for Windows software package (SAS Institute Inc. NC, USA) was used for statistical analysis. Additionally, in univariate analysis, the estimation of the effect and the related 95\% CI for the arithmetic characteristics was performed via the $\mathrm{R}$ language version 3.6.0.

\section{Results}

This study included a total of 187 HIV-infected patients; $170(90.9 \%)$ were male with $135(79.4 \%)$ of them being men who have sex with men (MSM). The patients' median age was 46 (range 20-85) years old and the median BMI 24.2 (range 18.3-38). Twenty-three (12.3\%) patients were intravenous drug users (IVDU) and 20 (10.7\%) patients had a history of alcohol abuse in the last 5 years. Seven patients were diabetic (3 of them on treatment) and $64(34.2 \%)$ had a history of hyperlipidemia (18 of them on treatment). Baseline characteristics, HIVrelated medical history, and laboratory results of the patients included in the study are shown in Table 1.

The median duration of HIV seropositivity was 84 months (range 1-381) with the commonest way of HIV acquisition being sex (163 patients, $87.1 \%$ ). The vast majority of the patients (85.6\%) were under ART, and the median duration of treatment was 84 months (range 2348). A total of 37 patients had a traceable viral load when TE was performed, with 27 of them not being under treatment and the other 10 having begun their ART during the last 6 months. One hundred thirteen (60.4\%) patients were classified as stage A, 35 (18.7\%) stage B and 39 (20.9\%) stage C, according to the CDC [25]. LREs occurred in a total of 60 (32.1\%) patients, with the commonest event being transaminasemia occurring in 44 patients (73.3\%). Full list of LREs is shown in Table 2.

Ten (5.3\%) patients were HBsAg positive, 20 (10.7\%) had traceable HCV RNA and 158 (84.5\%) were HIV mono-infected. Baseline laboratory results of the included patients are shown in Table 1. Twenty-three

Table 1 Patients' laboratory results

\begin{tabular}{|c|c|c|c|}
\hline Parameter & Mean \pm SD & (Min,Max) & Median (IQR) \\
\hline Age (years) & $46.2 \pm 11.5$ & $(20,85)$ & $46(38-53)$ \\
\hline HIV Duration (months) & $110.7 \pm 92.8$ & $(1,381)$ & $84(37-168)$ \\
\hline Duration of treatment (months) & $88.0 \pm 84.9$ & $(0,348)$ & $59.5(16-134)$ \\
\hline $\mathrm{BMI}$ & $24.6 \pm 3.5$ & $(18.3,38.0)$ & $24.2(22.3-26.4)$ \\
\hline ALP (IU/ml) & $73.6 \pm 25.6$ & $(9,180)$ & $70.0(56.0-85.0)$ \\
\hline ALT (IU/ml) & $32.7 \pm 29.8$ & $(8,286)$ & $24.0(20-32.5)$ \\
\hline AST (lu/ml) & $28.56 \pm 22.32$ & $(9,230)$ & $24.0(20.0-28.0)$ \\
\hline Bil (mg/dl) & $0.62 \pm 0.59$ & $(0.16,6.38)$ & $0.49(0.36-0.67)$ \\
\hline gGT (IU/ml) & $42.2 \pm 46.7$ & $(8,343)$ & $28.0(18.0-44.0)$ \\
\hline $\operatorname{PLTs}(k / \mu l)$ & $213,963 \pm 62,336$ & $(65,000,608,000)$ & $205,000(176,000-242,000)$ \\
\hline TRG $(\mathrm{mg} / \mathrm{dl})$ & $155.9 \pm 114.2$ & $(41,761)$ & $124.0(97.0-167.0)$ \\
\hline $\mathrm{CHOL}(\mathrm{mg} / \mathrm{dl})$ & $190.1 \pm 46.7$ & $(77,313)$ & $189.0(154.0-218.0)$ \\
\hline CD4 (cells/ $\mu \mathrm{L})$ & $697.6 \pm 380.7$ & $(10,1881)$ & $660.0(412.0-909.0)$ \\
\hline $\mathrm{CD} 4 / \mathrm{CD} 8$ & $0.70 \pm 0.42$ & $(0.03,2.22)$ & $0.65(0.38-0.95)$ \\
\hline Months of CD4 less than 50 cells/ $\mu \mathrm{L}$ & $1.48 \pm 9.2$ & $(0,120)$ & $0(0-0)$ \\
\hline Months of CD4 less than 200 cells/ $\mu \mathrm{L}$ & $6.71 \pm 20.43$ & $(0,240)$ & $0(0-6)$ \\
\hline Months of CD4 less than 350 cells/ $\mu \mathrm{L}$ & $19.22 \pm 35.76$ & $(0,289)$ & $5(0-20)$ \\
\hline Months of VL higher than $50 \mathrm{cop} / \mathrm{ml}$ & $31.48 \pm 43.85$ & $(0,225)$ & $12(5-39)$ \\
\hline Number of LREs & $0.42 \pm 0.78$ & $(0,5)$ & $0(0-1)$ \\
\hline Events of transaminasemia & $0.59 \pm 1.13$ & $(0,5)$ & $0(0-1)$ \\
\hline
\end{tabular}

BMI Body-mass index, ALP Alkaline phosphatase, ALT Alanine aminotransferase, AST Aspartate aminotransferase, Bil Total Bilirubin, $g G T$ gamma glutamyltransferase, PLTS platelets, TRG triglycerides, CHOL cholesterol, VL Viral load, LREs Liver related events. 
Table 2 List of Liver Related Events (LRES) by frequency of occurrence

\begin{tabular}{ll}
\hline LRE $\left(\boldsymbol{N}=60\right.$ patients $\left.^{a}\right)$ & $N(\%)$ \\
\hline Transaminasemia & $44(73.3)$ \\
Acute viral hepatitis & $3(5.0)$ \\
Portal vein thrombosis & $1(1.7)$ \\
Drug-induced liver injury & $3(5.0)$ \\
Hyperbiliruminemia & $4(6.7)$ \\
Other & $12(20 \%)$
\end{tabular}

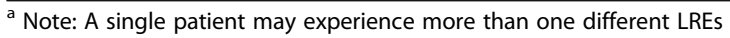

(12.3\%) and $37(19.8 \%)$ patients had abnormal serum levels of Aspartate aminotransferase (AST) and Alanine aminotransferase (ALT) respectively, 65 (34.8\%) patients abnormal serum levels of Gamma-glutamyl transferase ( $\gamma$-GT), 5 (2.7\%) of Alkaline phosphatase (ALP) and 10 (5.3\%) patients had high total bilirubin serum levels. Median CD4+ T cell count was 657.5 cells $/ \mathrm{mm}^{3}$ (range 101881). Four (2.1\%) patients of the total population had a CD4+ T cell count of less than 50 cells $/ \mathrm{mm}^{3}, 17$ (9.1\%) less than 250 cells $/ \mathrm{mm}^{3}$, and $38(20.3 \%)$ less than 350 cells $/ \mathrm{mm}^{3}$.

Median TE value was $5.1 \mathrm{KPa}$ (range 2.8-26.3), with 92.5\% (173/187) of the patients being placed in the no/ mild fibrosis group (equivalent to Metavir score of F0F2) and $7.4 \%(14 / 187)$ in the significant fibrosis one (equivalent to Metavir score of F3-F4).

In univariate analysis a higher prevalence of fibrosis was found in patients with higher serum levels of liver injury markers (ALT, AST, $\gamma$-GT), older age and increased number of episodes of transaminasemia in medical history. A positive correlation with high LS was also found in univariate analysis among patients with chronic $\mathrm{HCV}$ infection, diabetes mellitus, alcohol abuse and clinical AIDS (CDC stage C) (Table 3).

On the contrary, liver fibrosis stage was not correlated with BMI, gender, sexual orientation or HIV-relevant disease markers (CD4 count, CD4/CD8 ratio, HIV duration, duration of ART and ART-free duration of HIV infection, months of low CD4 count and viral load of more than $50 \mathrm{cop} / \mathrm{ml}$ ). Also no correlation was found with the drugs used in patients' ART (see appendix).

On multivariate logistic regression analysis, the model started with all studied variables, including those that had no significant impact on abnormal LS values in the univariate analysis. In a second step, having in mind that laboratory variables (AST, ALT, $\gamma$-GT, ALP, total and direct Bilirubin serum levels, platelets' count, total cholesterol, triglycerides and albumin serum levels) are the result and not the causative factors of liver injury, laboratory values were excluded from the analysis. The variables associated with higher LS values are shown on Table 4. These results show that the variables with most significant influence are those with a significant impact on abnormal LS in univariate analysis, with the only exception of CD4/CD8 ratio, which was not important in univariate analysis. When all variables were used, older age, lower CD4/CD8 ratio, higher AST values and higher number of events of transaminasemia accounted positively to higher probability for abnormal LS values (Table 3). When laboratory results were excluded both $\mathrm{HCV}$ co-infection and alcohol abuse appeared as important factors leading to higher LS values, while events of transaminasemia became statistically insignificant (Table 5).

Table 3 Univariate analysis of the study parameters that had a positive role for liver fibrosis. Only those that achieved statistical significance are presented

\begin{tabular}{|c|c|c|c|}
\hline Parameter & Effect estimate $^{a}$ & $95 \% \mathrm{Cl}$ & $\boldsymbol{P}$ value \\
\hline Age (years) & 0.023 & $0.0018-0.067$ & 0.0285 \\
\hline AST (IU/ml) & 0.083 & $0.020-0.17$ & 0.0003 \\
\hline ALT (IU/ml) & 0.034 & $0.0005-0.114$ & 0.0081 \\
\hline үGT (IU/ml) & 0.051 & $0.0057-0.13$ & 0.0012 \\
\hline LRE (Yes vs. No) & 4.6 & $1.5-14.3$ & 0.0051 \\
\hline Number of LRES & 0.038 & $0.0007-0.114$ & 0.0052 \\
\hline Events of transaminasemia & 0.060 & $0.0043-0.16$ & 0.0042 \\
\hline HCV co-infection (Yes vs. No) & 4.2 & $1.2-15.1$ & 0.0178 \\
\hline Alcohol overuse (Yes vs. No) & 3.9 & $1.1-13.9$ & 0.0244 \\
\hline Diabetes Mellitus (Yes vs. No) & 5.6 & $1.0-31.9$ & 0.0307 \\
\hline Clinical AIDS (Stage CDC - C vs. non C) & 4.4 & $1.4-13.4$ & 0.0055 \\
\hline
\end{tabular}

AST Aspartate Aminotransferase, ALT Alanine Aminotransferase $\gamma$-GT: Gamma Glutamyl Transpeptidase, LRE Liver related event, HCV Hepatitis C, AIDS Acquired Immune Deficiency Syndrome.

${ }^{a}$ Effect is reported as epsilon-square $\left(\varepsilon^{2}\right)$ and odds ratio for the arithmetic and categorical quantities respectively 
Table 4 Multivariate analysis of factors leading to significant liver fibrosis using all study's parameters

\begin{tabular}{lll}
\hline Parameter & Odds Ratio $(95 \% \mathrm{Cl})$ & $\mathrm{p}$ \\
\hline Age & $1.1(1.0-1.2)$ & 0.0023 \\
CD4 / CD8 ratio & $0.04(0.003-0.540)$ & 0.0151 \\
AST & $1.08(1.03-1.13)$ & 0.0026 \\
Events of transaminasemia & $2.3(1.2-4.5)$ & 0.0147 \\
\hline
\end{tabular}

AST Aspartate aminotransferase, Cl Confidence Interval

\section{Discussion}

HIV-infected patients live longer since the introduction of ART, but they remain a high-risk group for liver and cardiovascular diseases. HIV infection per se, HIV/HBV and $\mathrm{HIV} / \mathrm{HCV}$ coinfection, ART, diabetes mellitus, BMI and fatty liver infiltration, have all been associated with an increased risk of significant liver damage which leads to liver fibrosis. However, previously published data although largely agree that $\mathrm{HIV} / \mathrm{HCV}$ co-infection and older age are aggravating factors for significant liver fibrosis, disagree if HIV infection per se or ART drugs can cause chronic liver damage, leading to liver fibrosis [19-24].

To address these questions we conducted a study in a cohort of Greek, HIV-infected, patients, using TE to assess liver fibrosis. Our study using TE demonstrated a rate of no/mild fibrosis (equivalent to Metavir score of F0-F2) in $92.7 \%$ of the HIV-infected patients and significant fibrosis (equivalent to Metavir score of F3-F4) in $7.4 \%$ of them. Statistical analysis showed that presence of HIV/HCV co-infection, older patient's age, diabetes mellitus, AST levels and alcohol abuse were associated with the presence of significant liver fibrosis; a higher number of LREs had also a positive effect in it. As far as HIV infection per se is concerned, significant liver fibrosis was correlated with clinical AIDS (CDC staging C) while absolute CD4 count, duration of seropositivity,duration of low CD4 count (both under 350 as well as under 50 cells $/ \mathrm{mm}^{3}$ ) and duration of traceable viral load, were not associated with a higher risk of liver fibrosis.

In multivariate analysis, when all parameters were used, older age, AST levels and increased number of events of transaminasemia showed a correlation with

Table 5 Multivariate analysis of factors leading to significant liver fibrosis using all results but biochemical markers

\begin{tabular}{lll}
\hline Parameter & Odds Ratio $(95 \% \mathrm{Cl})$ & $\mathrm{p}$ \\
\hline Age & $1.1(1.0-1.2)$ & 0.0056 \\
Alcohol Overuse (Yes) & $9.90(1.9-50)$ & 0.0058 \\
HCV Infection (Yes) & $10.6(1.8-62.5)$ & 0.0091 \\
CD4 / CD8 ratio & $0.1(0.01-0.8)$ & 0.0251 \\
\hline
\end{tabular}

HCV Hepatitis C Virus, Cl Confidence Interval. significant fibrosis, while higher $\mathrm{CD} 4 / \mathrm{CD} 8$ ratio led to lower probability for high LS values. When biochemical values were excluded from multivariate analysis, both alcohol abuse and HIV/HCV co-infection rose as statistically significant fibrosis factors.

In our study univariate analysis indicated that high serum levels of 'liver damage' biomarkers $\gamma$-GT, AST and ALT correlated with higher LS values. However in multivariate analysis only AST serum levels seemed to correlate well with liver fibrosis. Even though that may seem a bit strange, this finding becomes logical when taking into account that in multivariate analysis HIV/ $\mathrm{HCV}$ co-infection and alcohol abuse rise as factors leading to high LS. Since both of them lead to higher AST levels with the progression of liver fibrosis, the abovementioned finding becomes logical.

Interestingly enough, our findings indicate that drugs used in ART, as well as both ART's and each drug's total duration are not associated with higher risk of liver fibrosis. Even though some ART drugs are accused for liver toxicity, especially those of the 'first generation' ART, this finding is not constant in studies made, since other ones, apart from our own, don't associate type of ART to significant liver fibrosis [20, 22]. Moreover no HIV-related parameters, other than CD4/ CD8 ratio, were correlated with liver fibrosis. The correlation of CD4/CD8 ratio with higher fibrosis risk is controversial. The $\mathrm{CD} 4 / \mathrm{CD} 8$ ratio in normal individuals ranges from 1.5 to 2.5 , and the low or inverted ratio is associated with altered immune function, immune senescence and chronic inflammation, as well as a variety of diseases, like neurocognitive disorders, lung cancer, and chronic obstructive pulmonary disease [30-37]. In HIV infected patients the chronic inflammation due to low CD4/CD8 ratio can possibly lead to chronic inflammation of the hepatocytes causing constant hepatocytes' death and regeneration, which, in long term, could lead to liver fibrosis. Despite this, studies done in $\mathrm{HCV} / \mathrm{HIV}$ coinfected and HIV mono-infected patients fail to agree in the involvement of low CD4/CD8 ratio in the liver damage of HIV-infected individuals [38-40].

The main limitations of our cross-sectional study are the small sample size of $\mathrm{HIV} / \mathrm{HCV}$ and HIV/HBV coinfected, as well as the rather small size of the HIV mono-infected patients with severe fibrosis (equivalent to Metavir score of F3-F4). Finally, although liver biopsy is the gold standard for the assessment of liver fibrosis, no liver biopsies were used for detection and staging of liver fibrosis, because of the poor acceptability and the risk of possible adverse effects; however TE was used, a noninvasive method that has been found to be accurate and reproducible in determining the stage of liver fibrosis. 


\section{Conclusions}

In conclusion, in $\mathrm{HIV}$-infected patients, $\mathrm{HCV}$ coinfection, older age, alcohol abuse and $\mathrm{CD} 4 / \mathrm{CD} 8$ ratio alone or in combination, seem to correlate with fibrogenesis in the liver.

\section{Supplementary information}

Supplementary information accompanies this paper at https://doi.org/10. 1186/s12876-020-01230-1.

\section{Additional file 1.}

\section{Abbreviations}

HIV: Human Immunodeficiency Virus; LS: Liver stiffness; TE: Transient Elastography; LREs: Liver Related Events; ART: Antiretroviral Treatment; HCV: Hepatitis C Virus; NRTIs: Nucleoside reverse transcriptase inhibitors; PIs: Protease Inhibitors; LFTs: Liver Function Tests; LB: Liver Biopsy; HDL: High Density Lipoproteins; LDL: Low Density Lipoproteins; TSH: Thyroid Stimulating Hormone; CDC: Centers for Disease Control and Prevention; ULN: Upper Limit of Normal; EBV: Epstein-Barr virus; HAV: Hepatitis A virus; HSV: Herpes simplex virus; VZV: Varicella zoster virus; AIDS: Acquired immune deficiency syndrome; KPa: Kilopascals; MSM: Men who have sex with men; IVDU: Intravenous drug users; AST: Aspartate Aminotransferase; ALT: Alanine Aminotransferase; $\gamma$-GT: Gamma-Glutamyl Transferase; ALP: Alkaline Phosphatase; HBV: Hepatitis B Virus

\section{Acknowledgements}

Not applicable.

\section{Authors' contribution}

TA and GH designed and supervised the study. NS, AK and TA collected the clinical data. MS conducted the transient elastographies. AP carried out the statistical analysis. TA, GH and NS drafted the manuscript. All authors have read and approved the final version of the manuscript.

\section{Funding}

No funding was obtained for this study.

\section{Availability of data and materials}

The datasets used and/or analyzed during the current study are available from the corresponding author on reasonable request.

\section{Ethics approval and consent to participate}

The protocol of the study has been reviewed and approved by 'Laiko University Hospital' ethics committee and written consent has been obtained by all enrolled patients. All study procedures were in agreement with the Declaration of Helsinki (Edinburgh, 2000).

\section{Consent for publication}

Not applicable.

\section{Competing interests}

The authors declare that there is no conflict of interests regarding the publication of this article.

\section{Author details}

'Department of Pathophysiology, Medical School, National and Kapodistrian University of Athens, Mikras Asias 75, 11527 Athens, Greece. ' 2 Liver unit, Euroclinic of Athens, Athens, Greece. '3econd Department of Pathology, Medical School, National and Kapodistrian University of Athens, Athens, Greece. ${ }^{4}$ Infectious Diseases Unit, Laiko General Hospital, Athens, Greece. ${ }^{5}$ Department of Pathophysiology, Medical School, National and Kapodistrian University of Athens, Athens, Greece. 'Department of Pathophysiology, Medical School, National and Kapodistrian University of Athens, Athens, Greece.
Received: 5 March 2019 Accepted: 24 March 2020

Published online: 06 April 2020

\section{References}

1. Global HIV \& AIDS statistics - 2018 fact sheet. http://www.unaids.org.

2. Antiretroviral Therapy Cohort Collaboration. Life expectancy of individuals on combination antiretroviral therapy in high-income countries: a collaborative analysis of 14 cohort studies. Lancet. 2008;372:293-9.

3. Antiretroviral Therapy Cohort Collaboration. Causes of death in HIV-1 infected patients treated with antiretroviral therapy 1996-2006: collaborative analysis of 13 HIV cohort studies. Clin Infect Dis. 2010;50(10):1387-96.

4. Smith CJ, Ryom L, Weber R, et al. Trends in underlying causes of death in people with HIV from 1999 to 2011 (D:a:D): a multicohort collaboration. Lancet. 2014;384(9939):241-8.

5. Joshi D, O'Grady J, Dieterich D, et al. Increasing burden of liver disease in patients with HIV infection. Lancet. 2011;377:1198-209.

6. Hernando V, Perez-Cachafeiro S, Lewden C, et al. All-cause and liver-related mortality in HIV positive subjects compared to the general population: differences by HCV co-infection. J Hepatol. 2012;57:743-51.

7. Alejos B, Hernando V, Lopez-Aldeguer J, et al. Overall and cause specific mortality in HIV-positive subjects compared to the general population. J Int AIDS Soc. 2014;17:19711.

8. Weber R, Sabin CA, Friis-Møller N, et al. Liver-related deaths in persons infected with the human immunodeficiency virus: the D:a:D study. Arch Intern Med. 2006;166:1632-41.

9. Soriano V, Barreiro P, Sherman KE. The changing epidemiology of liver disease in HIV patients. AIDS Rev. 2013;15(1):25-31.

10. The French METAVIR Cooperative Study Group. Intraobserver and interobserver variations in liver biopsy interpretation in patients with chronic hepatitis C. Hepatology. 1994;20:15-20.

11. Ratziu V, Charlotte F, Heurtier A, et al. Sampling variability of liver biopsy in nonalcoholic fatty liver disease. Gastroenterology. 2005;128:1898-906.

12. Seeff LB, Everson GT, Morgan TR, et al. Complication rate of percutaneous liver biopsies among persons with advanced chronic liver disease in the HALT-C trial. Clin Gastroenterol Hepatol. 2010:8:877-83.

13. Piccinino F, Sagnelli E, Pasquale G, et al. Complications following percutaneous liver biopsy: a multicentre retrospective study on 68,276 biopsies. J Hepatol. 1986;2:165-73.

14. Cross TJ, Calvaruso V, Maimone $\mathrm{S}$, et al. Prospective comparison of Fibroscan, King's score and liver biopsy for the assessment of cirrhosis in chronic hepatitis C infection. J Viral Hepat. 2010;17(8):546-54.

15. Pavlov CS, Casazza G, Nikolova D, et al. Transient elastography for diagnosis of stages of hepatic fibrosis and cirrhosis in people with alcoholic liver disease. Cochrane Database Syst Rev. 2015;1:CD010542.

16. Kamarajah SK, Chan WK, Nik Mustapha NR, et al. Repeated liver stiffness measurement compared with paired liver biopsy in patients with nonalcoholic fatty liver disease. Hepatol Int. 2018;12(1):44-55.

17. Castera L, Forns $X$, Alberti A. Non-invasive evaluation of liver fibrosis using transient elastography. J Hepatol. 2008;48(5):835-47.

18. Cassinotto C, Boursier J, de Lédinghen V, et al. Liver stiffness in nonalcoholic fatty liver disease: a comparison of supersonic shear imaging, FibroScan, and ARFI with liver biopsy. Hepatology. 2016;63(6):1817-27.

19. Han SH, Kim SU, Kim CO, et al. Abnormal Liver Stiffness Assessed Using Transient Elastography (Fibroscan) in HIV-Infected Patients without HBV/HCV Coinfection Receiving Combined Antiretroviral Treatment. PLoS One. 2013; 8(1):e52720

20. Brescini L, Orsetti E, Gesuita R, et al. Evaluating liver fibrosis by transient Elastometry in patients with HIV-HCV Coinfection and Monoinfection. Hepat Mon. 2014;14(8):e15426.

21. Maggi P, Altizio S, DI Biagio A, et al. Prevalence and risk factors for significant liver fibrosis in patients with HIV infection. In Vivo. 2015;29(6): $771-5$.

22. Blanco F, Barreiro $P$, Ryan $P$, et al. Risk factors for advanced liver fibrosis in HIV-infected individuals: role of antiretroviral drugs and insulin resistance. $J$ Viral Hepat. 2011;18(1):11-6.

23. Sagir A, Glaubach B, Sahin K, et al. Transient Elastography for the detection of liver damage in patients with HIV. Infect Dis Ther. 2015:4(3):355-64.

24. Sterling RK, Chiu S, Snider K, Nixon D. The prevalence and risk factors for abnormal liver enzymes in HIV-positive patients without hepatitis B or C coinfections. Dig Dis Sci. 2008;53:1375-82. 
25. Schneider E, Whitmore S, Glynn KM, et al. Revised surveillance case definitions for HIV infection among adults, adolescents, and children aged $<18$ months and for HIV infection and AIDS among children aged 18 months to $<13$ years--United States, 2008. MMWR Recomm Rep. 2008;57(RR-10):1-12

26. American Diabetes Association. 2. Classification and diagnosis of diabetes: Standards of Medical Care in Diabetes-2018. Diabetes Care. 2018;41(Suppl. 1):S13-27.

27. Jellinger PS, Handelsman Y, Rosenblit PD, et al. American association of clinical endocrinologists and American College of Endocrinology Guidelines for management of dyslipidemia and prevention of cardiovascular disease. Endocr Pract. 2017;23(Suppl 2):1-87.

28. National Institute on Alcohol Abuse and Alcoholism. Helping patients who drink too much: A clinician's guide. NIH Publication no. 05-3769, Bethesda, MD 2005. https://www.niaaa.nih.gov/sites/default/files/ publications/guide.pdf.

29. Tomczak M, Tomczak E. The need to report effect size estimates revisited. An overview of some recommended measures of effect size. Trends in Sport Sciences. 2014;1(21):19-25.

30. Amadori A, Zamarachi R, De Silvestro G, et al. Genetic control of the CD4/ CD8 T-cell ratio in humans. Nat Med. 1995;1(12):1279-83.

31. Evans DM, Zhu G, Duffy DL, et al. A major quantitative trait locus for CD4/ CD8 ratio is located on chromosome 11. Genes Immun. 2004;5(7):548-52.

32. Howard RR, Fasano CS, Frey L, et al. Reference intervals of CD3, CD4, CD8, CD4/CD8, and absolute CD4 values in Asian and non-Asian populations. Cytometry, 1996:26(3):231-2.

33. Wikby A, Månsson IA, Johansson B, et al. The immune-risk profile is associated with age and gender: findings from three Swedish population studies of individuals 20 \pm 100 years of age. Biogerontology. 2008;9:299-308.

34. Vassallo M, Durant J, Lebrun-Frenay C, et al. Virologically suppressed patients with asymptomatic and symptomatic HIV associated neurocognitive disorders do not display the same pattern of immune activation. HIV Med. 2015;16(8):431-40.

35. Sigel K, Wisnivesky J, Crothers $\mathrm{K}$, et al. Immunological and infectious risk factors for lung cancer in US veterans with HIV: a longitudinal cohort study. Lancet HIV. 2017;4(2):e67 \pm 73 .

36. Triplette M, Attia EF, Akgun KM, et al. A low peripheral blood CD4/CD8 ratio is associated with pulmonary emphysema in HIV. PLoS One. 2017;12(1): e0170857.

37. Badejo O, Chang C, So-Armah KA, et al. CD8+T-cells count in acute myocardial infarction in HIV disease in a predominantly male cohort. Biomed Res Int. 2015;2015:246870.

38. Feuth $T$, van Baarle $D$, van Erpecum KJ, et al. CD4/CD8 ratio is a promising candidate for non-invasive measurement of liver fibrosis in chronic HCVmonoinfected patients. Eur J Clin Microbiol Infect Dis. 2014;33(7):1113-7.

39. Hansen S, Kronborg G, Benfield T. Prediction of liver disease, AIDS, and mortality based on discordant absolute and relative peripheral CD4 T lymphocytes in HIV/hepatitis C virus-Coinfected individuals. AIDS Res Hum Retrovir. 2018;23.

40. Chiou YL, Shih CJ, Ko WS. The increased ratio of CD4+/CD8+ was positively correlated with inflammation in hepatitis $C$ patients with metabolic syndrome. Clin Biochem. 2013;46(9):745-9.

\section{Publisher's Note}

Springer Nature remains neutral with regard to jurisdictional claims in published maps and institutional affiliations.

Ready to submit your research? Choose BMC and benefit from:

- fast, convenient online submission

- thorough peer review by experienced researchers in your field

- rapid publication on acceptance

- support for research data, including large and complex data types

- gold Open Access which fosters wider collaboration and increased citations

- maximum visibility for your research: over $100 \mathrm{M}$ website views per year

At BMC, research is always in progress.

Learn more biomedcentral.com/submissions 